\title{
Theoretical Study with Rovibrational and Dipole Moment Calculation of the SiO Molecule
}

\author{
Khalil Badreddine ${ }^{1}$, Nayla El-Kork ${ }^{2}$, Mahmoud Korek ${ }^{1^{*}}$ \\ ${ }^{1}$ Faculty of Science, Beirut Arab University, Beirut, Lebanon \\ ${ }^{2}$ Khalifa University, Sharjah, UAE \\ Email: "fkorek@yahoo.com
}

Received October 20, 2012; revised November 21, 2012; accepted November 30, 2012

\begin{abstract}
Via CASSCF/MRCI and RSPT2 calculations (single and double excitation with Davidson correction) the potential energy curves of 20 electronic states in the representation ${ }^{2 \mathrm{~S}+1} \Lambda^{( \pm)}$of the molecule $\mathrm{SiO}$ have been calculated. By fitting these potential energy curves to a polynomial around the equilibrium internuclear distance $r_{e}$, the harmonic frequency $\omega_{e}$, the rotational constant $B_{e}$, and the electronic energy with respect to the ground state $T_{e}$ have been calculated. For the considered electronic states the permanent dipole moment $\mu$ have been plotted versus the internuclear distance $r$. Based on the canonical functions approach, the eigenvalues $E_{v}$, the rotational constant $B_{v}$ and the abscissas of the turning points $r_{\min }$ and $r_{\max }$ have been calculated. The comparison of these values to the experimental and theoretical results available in the literature is presented. In the present work 8 higher electronic states have been studied theoretically for the first time.
\end{abstract}

Keywords: Ab Initio Calculation; SiO Molecule; Potential Energy Curves; Spectroscopic Constants; Dipole Moment; Rovibrational Calculation

\section{Introduction}

The silicon monoxide $\mathrm{SiO}$ molecule is of considerable astrophysical interest, it is detected in the interstellar medium and in a variety of astrophysical objects which are mostly associated with warm, dense, and shocked gas [1]. Because of the interaction between high velocities jets emerging from a young star and the surrounding molecular environment a large fraction of the silicon monoxide relative to hydrogen molecule are found in the high velocity gas components of molecular outflows [2]. This abundance of $\mathrm{SiO}$ comes from the sputtering of dust grains in shocked regions and the subsequent release of Si-bearing material into the gas phase [3-7].

In recent years silica nanoparticles has attracted considerable attention due to their potential applications in many fields including ceramics, chromatography, catalysis and chemical mechanical polishing [8], nanodevices and mesoscopic research [9]. Altman et al. [9] probed the behavior of light absorption of silica nanoparticles at high temperatures in the Urbach region, and compare it with that in bulk materials. They assumed that, the $\mathrm{SiO}$ vapor emission does not contribute significantly to the flame radiation in visible. This can be easily justified by considering that the lower state of a $\mathrm{SiO}$ molecule in-

"Corresponding author. volved in transitions in visible light is not a ground state of the $\mathrm{SiO}$ molecule, but a highly excited one [10].

By studying the published data in literature on the molecule SiO, one can notice the large discrepancy between these values either theoretical or experimental. The values of the electronic transition energy $T_{e}$ with respect to the ground state $\mathrm{X}^{1} \Sigma^{+}$vary as

$24115 \mathrm{~cm}^{-1} \leq T_{e} \leq 24031 \mathrm{~cm}^{-1}$,

$25509 \mathrm{~cm}^{-1} \leq T_{e} \leq 24031.82 \mathrm{~cm}^{-1} \quad$ [12],

and $32978.9 \mathrm{~cm}^{-1} \leq T_{e} \leq 45135 \mathrm{~cm}^{-1}$ [12] respectively for the electronic states $(1)^{3} \Sigma^{+},(1)^{3} \Sigma^{+},(2)^{3} \Sigma$. Similar data can be found for different spectroscopic constants of different electronic states. Stimulated by these discrepancies, the important connection between energy relations of solids and molecules [13], and based on our previous theoretical calculation [14-23], we performed an ab initio study of the low-lying electronic states of the molecule $\mathrm{SiO}$ below $132,500 \mathrm{~cm}^{-1}$. In this work, we investigate the potential energy curves (PECs), the electric dipole moment and spectroscopic constants for the $20{ }^{2 \mathrm{~S}+1} \Lambda^{ \pm}$lowlying electronic states of this molecule obtained by MRCI and RSPT2 calculations. Taking advantage of the electronic structure of the investigated electronic states of the $\mathrm{SiO}$ molecule and by using the canonical functions approach [24-26], the eigenvalues $E_{v}$, the rotational 
constant $B_{v}$ and the abscissas of the turning points $r_{\min }$ and $r_{\max }$ have been calculated up to the vibrational level $v=$ 52.

\section{Computational Approach}

\subsection{Ab Initio Calculation}

The PECs of the lowest-lying electronic states of $\mathrm{SiO}$ molecule have been investigated via CASSCF method. MRCI and RSPT2 calculations (single and double excitations with Davidson corrections) were performed. Silicon atom is treated in all electron schemes where the 14 electrons of the silicon atom are considered using the cc-PVTZ basis set including s, p, $\mathrm{d}$ and f functions [27]. The oxygen atom is treated in all electron schemes where the 8 electrons of the oxygen atom are considered using the DGauss- $\mathrm{a}_{2}$-Xfit basis set including $\mathrm{s}, \mathrm{p}$ and $\mathrm{d}$ functions [28]. Among the 22 electrons explicitly considered for the $\mathrm{SiO}$ molecule (14 electrons for $\mathrm{Si}$ and 8 for $\mathrm{O}$ ), 18 inner electrons were frozen in subsequent calculations so that 4 valence electrons were explicitly treated. This calculation has been performed via the computational chemistry program MOLPRO [29] taking advantage of the graphical user interface GABEDIT [30].
The PECs for the 20 electronic states in the representation ${ }^{2 \mathrm{~S}+1} \Lambda^{( \pm)}$obtained from MRCI calculation have been obtained for 222 internuclear distances in the range $1.06 \AA \leq r \leq 4.00 \AA$. These potential energy curves for the singlet, triplet and quintet electronic states in the different symmetries are given, respectively in Figures 1-3.

The spectroscopic constants such as the vibration harmonic constants $\omega_{e}$ and $\omega_{e} x_{e}$, the internuclear distance at equilibrium $r_{e}$, the rotational constant $B_{e}$, and the electronic transition energy with respect to the ground state $T_{e}$ have been calculated by fitting the energy values around the equilibrium position to a polynomial in terms of the internuclear distance. These values are given in Table 1 together with the available values in the literature either theoretical or experimental. The comparison of our MRCI calculated values of $r_{e} \omega_{e}$, and $B_{e}$ for the ground state $\mathrm{X}^{1} \Sigma^{+}$with those given in literature, either theoretical or experimental, shows an excellent agreement with the relative differences

$$
\begin{aligned}
& 0.05 \%\left({ }^{\left({ }^{\text {Fit })}\right.} \operatorname{Ref} .[6]\right) \leq \frac{\delta r_{e}}{r_{e}} \leq 2.9 \%\left({ }^{(\mathrm{SCF})} \operatorname{Ref} .[35]\right) \\
& 0.6 \%\left({ }^{\left({ }^{\mathrm{MSCF}} 30\right)} \operatorname{Ref} .[35]\right) \leq \frac{\delta \omega_{e}}{\omega_{e}} \leq 10.7 \%\left({ }^{\left({ }^{\mathrm{MP} 2}-1\right)} \operatorname{Ref} .[33]\right),
\end{aligned}
$$

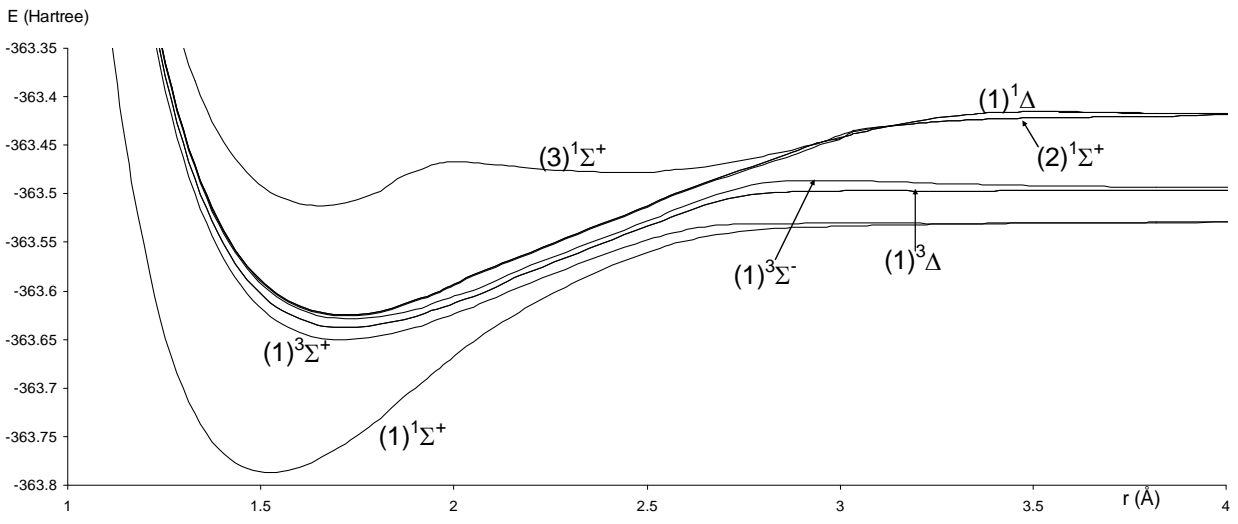

Figure 1. Potential energy curves of the lowest singlet and triplet $\Sigma$ and $\Delta$-states of the molecule SiO.

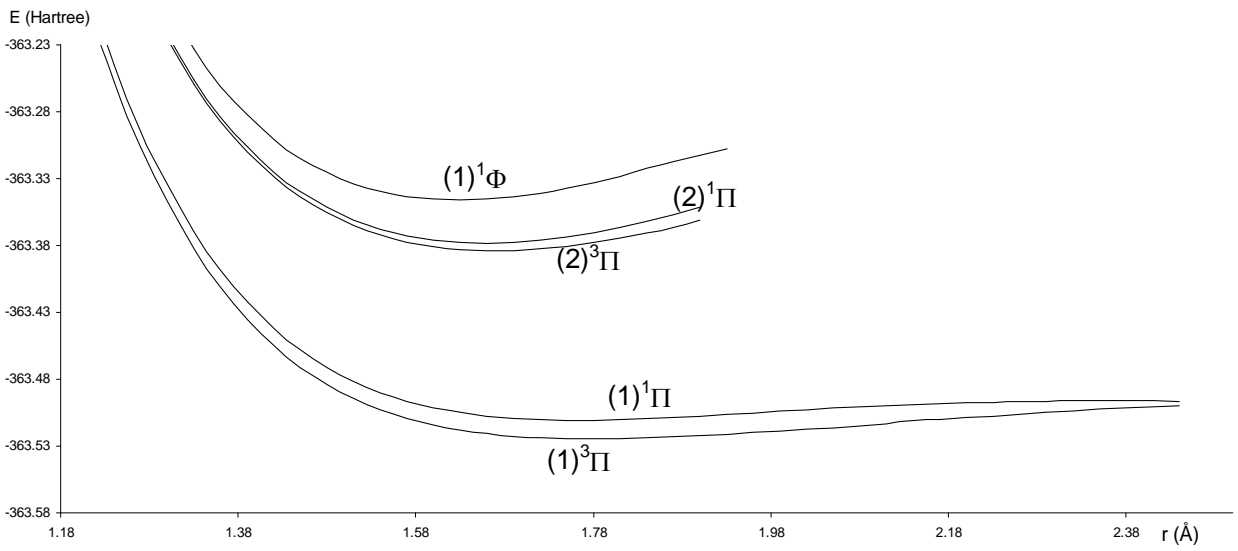

Figure 2. Potential energy curves of the lowest singlet and triplet $\Sigma$ and $\Delta$-states of the molecule $\mathrm{SiO}$. 


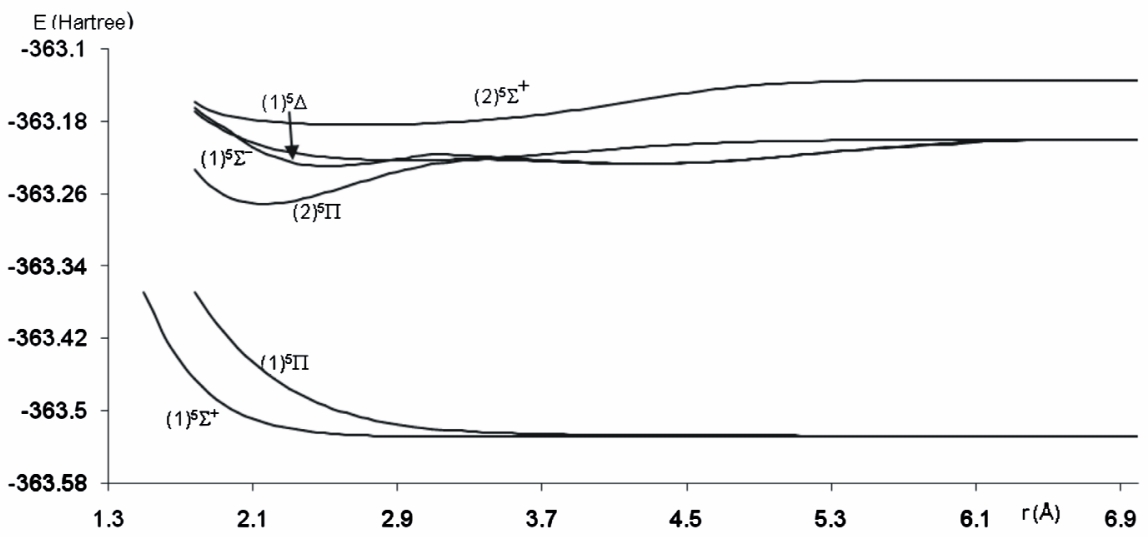

Figure 3. Potential energy curves of the lowest quintet states of the molecule SiO.

Table 1. Spectroscopic constants for the electronic states of the molecule SiO.

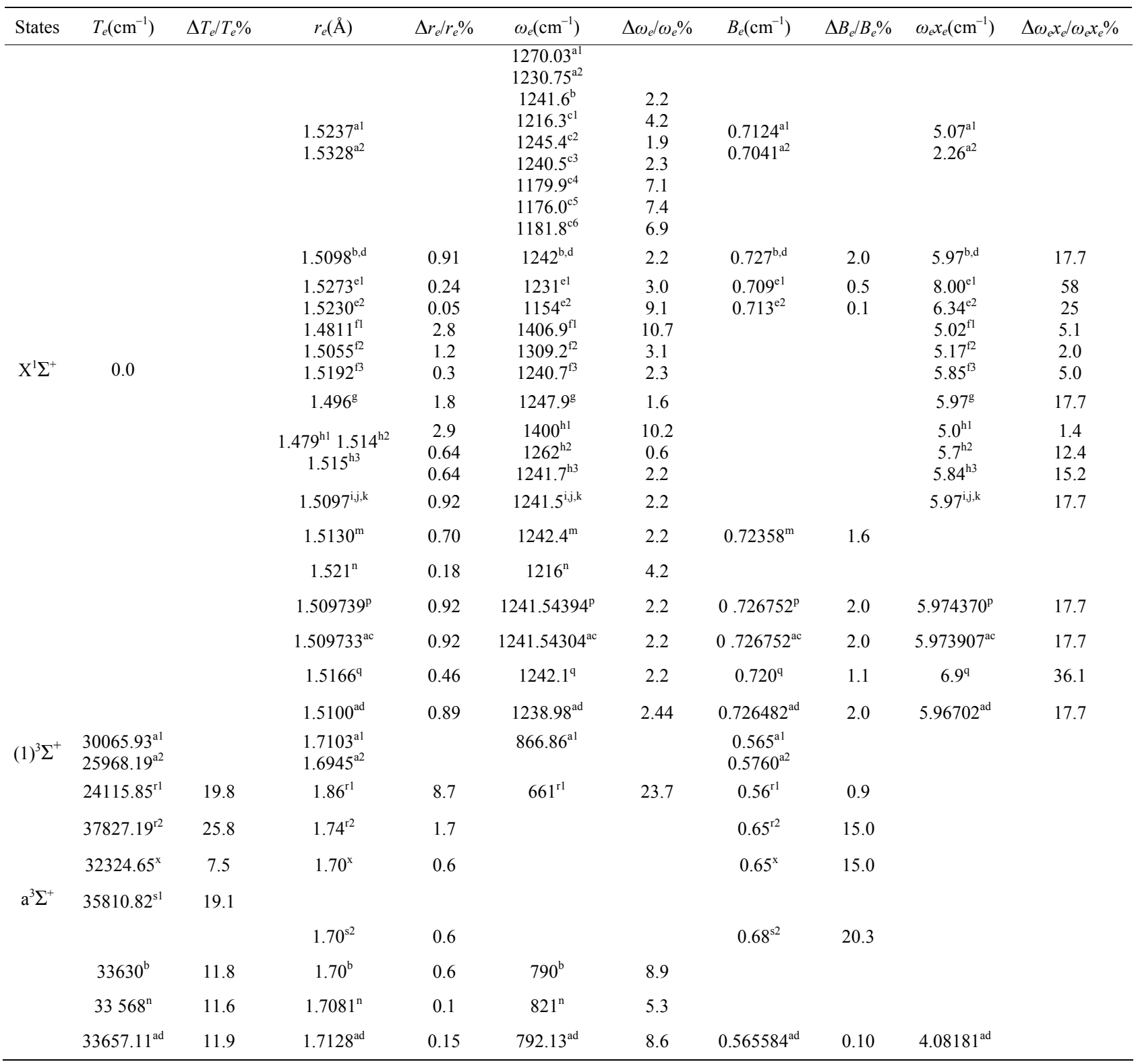


Continued

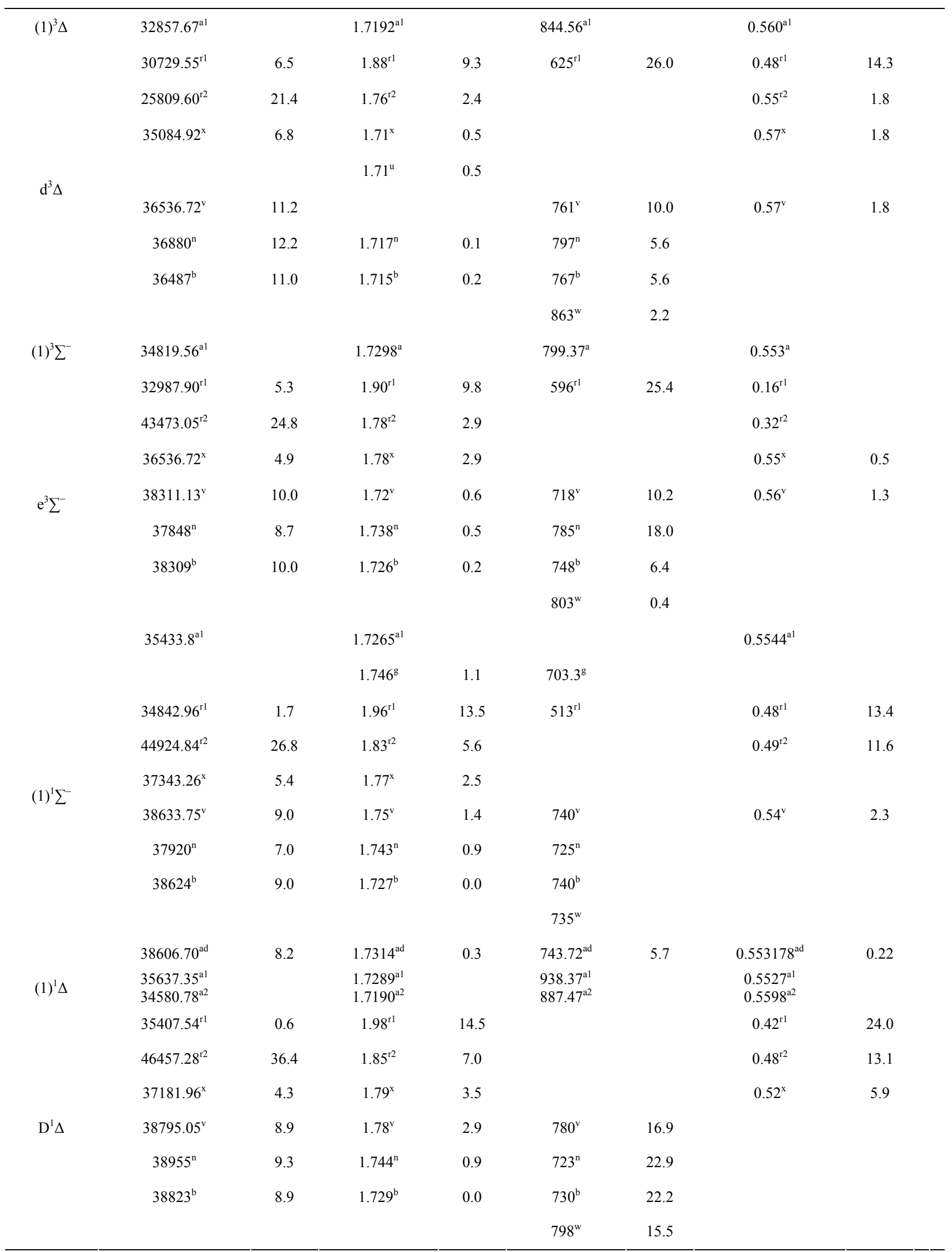


Continued

\begin{tabular}{|c|c|c|c|c|c|c|c|c|}
\hline $3 \Pi$ & $57708.29^{\mathrm{a} 1}$ & & $1.7683^{\mathrm{a} 1}$ & & $583.90^{\mathrm{a} 1}$ & & $0.5286^{\mathrm{a} 1}$ & \\
\hline \multirow{2}{*}{${ }^{3} \Pi(\mathrm{III})$} & $65007.93^{x}$ & 12.6 & $1.64^{\mathrm{x}}$ & 7.3 & & & $0.61^{x}$ & 15.4 \\
\hline & $59604.05^{z}$ & 3.3 & 1. $70^{z}$ & 3.9 & $482^{z}$ & 17.4 & $0.57^{z}$ & 7.8 \\
\hline \multirow[t]{2}{*}{$(2)^{1} \Sigma^{+}$} & $\begin{array}{l}60430.60^{\mathrm{a} 1} \\
65311.28^{\mathrm{a} 2}\end{array}$ & & $\begin{array}{l}1.6544^{\mathrm{a} 1} \\
1.6499^{\mathrm{a} 2}\end{array}$ & & $\begin{array}{l}935.16^{\mathrm{a} 1} \\
947.04^{\mathrm{a} 2}\end{array}$ & & $\begin{array}{l}0.6049^{\mathrm{a} 1} \\
0.6076^{\mathrm{a} 2}\end{array}$ & \\
\hline & $68718.06^{\mathrm{rl}}$ & 13.7 & $2.29^{\mathrm{rl}}$ & 38.4 & & & $0.32^{\mathrm{r} 1}$ & \\
\hline \multirow[t]{2}{*}{$\mathrm{F}^{1} \Sigma^{+}$} & $63878.76^{x}$ & 5.7 & $1.62^{\mathrm{x}}$ & 2.1 & $1934^{x}$ & & $0.63^{x}$ & 4.1 \\
\hline & $68395.44^{\mathrm{ab}}$ & 13.2 & $1.60^{\mathrm{ab}}$ & 3.3 & $1105^{\mathrm{ab}}$ & 18.2 & $0.64^{\mathrm{ab}}$ & 5.8 \\
\hline \multirow[t]{2}{*}{$(1)^{1} \Pi$} & $\begin{array}{l}60679.12^{\mathrm{a} 1} \\
58794.03^{\mathrm{a} 2}\end{array}$ & & $\begin{array}{l}1.7500^{\mathrm{a} 1} \\
1.8160^{\mathrm{a} 2}\end{array}$ & & $\begin{array}{l}750.77^{\mathrm{a} 1} \\
491.22^{\mathrm{a} 2}\end{array}$ & & $\begin{array}{l}0.5392^{\mathrm{a} 1} \\
0.5010^{\mathrm{a} 2}\end{array}$ & \\
\hline & & & $1.644^{\mathrm{g}}$ & 6.1 & $813.5^{\mathrm{g}}$ & 8.3 & & \\
\hline \multirow{4}{*}{$\mathrm{A}^{1} \Pi$} & $43863^{\mathrm{n}}$ & 27.7 & $1.650^{\mathrm{n}}$ & 5.7 & $813^{\mathrm{n}}$ & 8.3 & & \\
\hline & $42835.4^{\mathrm{b}}$ & 29.4 & $1.6206^{\mathrm{b}}$ & 7.4 & $852.8^{\mathrm{b}}$ & 13.4 & & \\
\hline & $42961.96^{\mathrm{ad}}$ & 7.3 & $1.6229^{\text {ad }}$ & & $851.99^{\text {ad }}$ & $0.63^{\text {ad }}$ & & $5.73^{\mathrm{ad}}$ \\
\hline & $62668.94^{\mathrm{r} 1}$ & 3.3 & $2.10^{\mathrm{rl}}$ & 20.0 & $803^{\mathrm{rl}}$ & 6.9 & $0.37^{\mathrm{rl}}$ & \\
\hline \multirow[t]{2}{*}{$\mathrm{G}^{1} \Pi$} & $65169.24^{x}$ & 7.4 & $1.59^{x}$ & 9.1 & $733^{x}$ & 2.4 & $0.66^{\mathrm{x}}$ & 22.4 \\
\hline & $69443.96^{\mathrm{y}}$ & 14.4 & $1.62^{\mathrm{y}}$ & 7.4 & $863^{y}$ & 14.9 & $0.63^{y}$ & 16.8 \\
\hline$(2)^{3} \Delta$ & $65452.41^{\mathrm{a} 2}$ & & $2.2928^{\mathrm{a} 2}$ & & $444.52^{\mathrm{a} 2}$ & & $0.3143^{\mathrm{a} 2}$ & \\
\hline$(1)^{3} \Gamma$ & $65602.38^{\mathrm{a} 2}$ & & $2.3971^{\mathrm{a} 2}$ & & $583.8^{\mathrm{a} 2}$ & & $0.2878^{\mathrm{a} 2}$ & \\
\hline$(1)^{1} \Gamma$ & $76322.36^{\mathrm{a} 2}$ & & $3.7182^{\mathrm{a} 2}$ & & $187.11^{\mathrm{a} 2}$ & & $0.1195^{\mathrm{a} 2}$ & \\
\hline$(3)^{1} \Gamma$ & $82511.00^{\mathrm{a}}$ & & $\begin{array}{c}1.8508^{\mathrm{a} 2} \\
1.779^{\mathrm{g}}\end{array}$ & 3.9 & $\begin{array}{c}1338.96^{\mathrm{a} 2} \\
620.0^{\mathrm{g}}\end{array}$ & & $0.4829^{\mathrm{a} 2}$ & \\
\hline$(3)^{3} \Pi$ & $88538.96^{\mathrm{a} 1}$ & & $1.6667^{\mathrm{a} 1}$ & & $887.135^{\mathrm{a} 1}$ & & $0.5958^{\mathrm{a} 1}$ & \\
\hline$(2)^{1} \Pi$ & $89827.23^{\mathrm{a} 1}$ & & $1.6592^{\mathrm{a} 1}$ & & $873.72^{\mathrm{a} 1}$ & & $0.6015^{\mathrm{a} 1}$ & \\
\hline$(1)^{1} \Phi$ & $96905.19^{\mathrm{al}}$ & & $1.6286^{\mathrm{a} 1}$ & & $1003.01^{\mathrm{a} 1}$ & & $0.6237^{\mathrm{a} 1}$ & \\
\hline$(2)^{5} \Pi$ & $113278.88^{\mathrm{a} 1}$ & & $2.1573^{\mathrm{a} 1}$ & & $484.12^{\mathrm{a} 1}$ & & $0.3554^{\mathrm{a} 1}$ & \\
\hline$(1)^{5} \Sigma^{-}$ & $122498.94^{\mathrm{a} 1}$ & & $2.5163^{\mathrm{a} 1}$ & & $340.09^{\mathrm{a} 1}$ & & $0.2612^{\mathrm{a} 1}$ & \\
\hline$(1)^{5} \Delta$ & $123876.23^{\mathrm{a} 1}$ & & $2.9340^{\mathrm{a} 1}$ & & $148.81^{\mathrm{a} 1}$ & & $0.1922^{\mathrm{a} 1}$ & \\
\hline$(2)^{5} \Sigma$ & $132432.98^{\mathrm{a} 1}$ & & $2.6970^{\mathrm{a} 1}$ & & $128.29^{\mathrm{a} 1}$ & & $0.2254^{\mathrm{al}}$ & \\
\hline
\end{tabular}

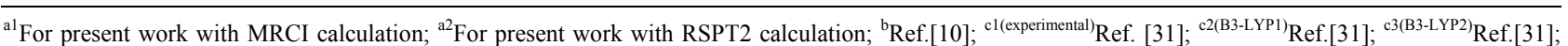

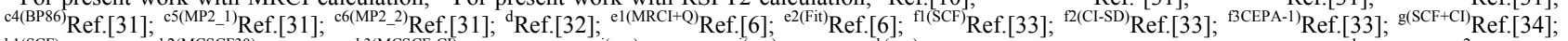

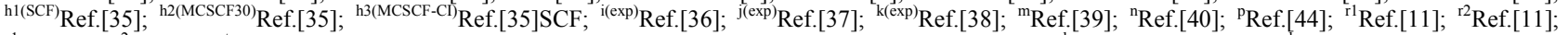

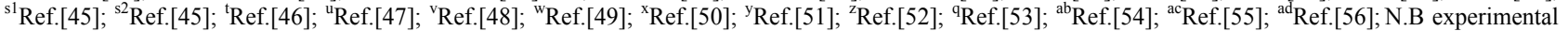
value $\mathrm{c} 1$ (Ref.[ 31]) is in solid methane. 


$$
0.1 \%\left({ }^{(\mathrm{Fit})} \operatorname{Ref} .[6]\right) \leq \frac{\delta B_{e}}{B_{e}} \leq 2.0 \%(\text { Refs. }[10,32,44,55]) .
$$

The agreement becomes less by comparing our calculated value of $\omega_{e} x_{e}$ with the experimental values of literature $[10,32,36-38,44,55]$ where the relative difference $\frac{\delta \omega_{e}}{\omega_{e}}=17.7 \%$. One can notice that, the theoretical value of $\omega_{e} x_{e}$ published in literature varies between 5.0 $\mathrm{cm}^{-1}$ and $8.0 \mathrm{~cm}^{-1}$ for the ground state [6,33-35]. The comparison of our calculated values by using the RSPT2 and MRCI techniques with those available in literature for the spectroscopic constants $r_{e}, \omega_{e}$ and $B_{e}$ shows the average values

$$
\begin{aligned}
& \left(\frac{\delta r_{e}}{r_{e}}=0.97 \%\right)_{\mathrm{MRCI}},\left(\frac{\delta r_{e}}{r_{e}}=1.54 \%\right)_{\mathrm{RSPT} 2}, \\
& \left(\frac{\delta \omega_{e}}{\omega_{e}}=4.0 \%\right)_{\mathrm{MRCI}},\left(\frac{\delta \omega_{e}}{\omega_{e}}=3.0 \%\right)_{\mathrm{RSPT} 2}, \\
& \left(\frac{\delta B_{e}}{B_{e}}=1.33 \%\right)_{\mathrm{MRCI}},\left(\frac{\delta B_{e}}{B_{e}}=2.37 \%\right)_{\mathrm{RSPT} 2} .
\end{aligned}
$$

From theseresults one can find that, the RSPT2 technique may gives better value for $\omega_{e}$ while MRCI technique gives better values for $r_{e}$ and $B_{e}$ for the ground state of the molecule $\mathrm{SiO}$.

By comparing our calculated values of $T_{e}$ for the states $(1)^{3} \Sigma^{+},(1)^{3} \Sigma,(1)^{3} \Sigma^{-},(1)^{1} \Sigma^{-},(1)^{1} \Sigma,(2)^{1} \Sigma$ with those obtained experimentally in literature one can find an overall acceptable agreement with relative difference

$8.9 \% \leq \frac{\delta T_{e}}{T_{e}} \leq 11.8 \%$ in Refs.[10,36] and larger relative difference for the states $(1)^{3} \Sigma^{+}$, (2) $)^{1} \Sigma$ given in Refs.[33, $39,43]$ with relative difference $13.2 \% \leq \frac{\delta T_{e}}{T_{e}} \leq 19.1 \%$. One can notice that, the comparison of our calculated value of $T_{e}$, for the considered electronic states, with those calculated in literature shows an excellent agreement by using one technique of calculation with $\frac{\delta T_{e}}{T_{e}}=0.6 \%$ (Ref.[11]) and disagreement by using another technique with $\frac{\delta T_{e}}{T_{e}}=36 \%$ (Ref.[11]) for the same state $(1)^{1} \Sigma$. Concerning the assignment of our calculated value of the ${ }^{1} \Sigma$ state, it is in good agreement with the calculated values of $G^{1} \Sigma$ state [32,38] and acceptable agreement with the experimental value given in Ref.[39]. The comparison of our values of $T_{e}$ with the newly published theoretical work by using the MRCI approach [56] shows an acceptable agreement for the 2 excited electronic states $(1)^{3} \Sigma^{+}$and $(1)^{1} \Sigma^{-}$with relative differences
$11.9 \%$ and $8.2 \%$ respectively.

The comparison of our calculated values of $r_{e}, \omega_{e}$, and $B_{e}$, for the excited states, with those given in literature experimentally $[10,48,51,54]$ shows that, our values of $r_{e}$ and $B_{e}$ are in very good agreement for all the investigated states with

$$
\begin{aligned}
& 0.0 \%(\text { Ref.[10] }) \leq \frac{\delta r_{e}}{r_{e}} \leq 7.4 \%(\operatorname{Ref} .[51]) \text { and } \\
& 1.3 \%\left(\text { Ref.[48]) } \leq \frac{\delta B_{e}}{B_{e}} \leq 2.3 \%(\operatorname{Ref} .[48])\right. \text { except the }
\end{aligned}
$$

value of $B_{e}$ for the state $\mathrm{G}^{1}$ where $\frac{\delta B_{e}}{B_{e}}=16.8 \%$. Our

values of $\omega_{e}$ are also in very good agreement with the experimental values for the electronic states with $T_{e} \leq 35434 \mathrm{~cm}^{-1}$ and becomes larger for the other investigated electronic states with

$$
14.9 \%(\operatorname{Ref} .[51]) \leq \frac{\delta \omega_{e}}{\omega_{e}} \leq 22.2 \%(\operatorname{Ref} .[10]) \text {. }
$$

Similarly, by comparing our calculated values of $r_{e} \omega_{e}$, and $B_{e}$ with those calculated in literature, one can notice that an excellent agreement by using one technique of calculation with relative differences $\frac{\delta r_{e}}{r_{e}}=0.1 \%$ for the state $(1)^{3} \Sigma^{+}$(Ref.[40]), $\frac{\delta \omega_{e}}{\omega_{e}}=2.2 \%$ for the state $(1)^{3} \Sigma$ (Ref.[49]), and $\frac{\delta B_{e}}{B_{e}}=0.5 \%$ for the state $(1)^{3} \Sigma^{-}$(Ref. [50]) and disagreement by using another technique with $\frac{\delta r_{e}}{r_{e}}=38.41 \%$ for the state $(2)^{1} \Sigma^{+}$(Ref.[11]), $\frac{\delta \omega_{e}}{\omega_{e}}=26.0 \%$ for the state $(1)^{3} \Sigma(\operatorname{Ref} .[11])$, and $\frac{\delta B_{e}}{B_{e}}=24.0 \%$ for the state $(1)^{1} \Sigma$ (Ref.[11]). These discrepancies in the theoretical results can be referred to the basis used in this calculation, the number of valence electron, the software used, the bad assignment of a state ....etc. While the comparison with the recent results of Ref.[56] for the 2 states $(1)^{3} \Sigma^{+}$and $(1)^{1} \Sigma^{-}$by using an approach similar to that we used in the present work shows an excellent agreement for the values of $r_{e}$ and $B_{e}$ and good agreement for $\omega_{e}$. For the state ${ }^{1} \Sigma$, there is an excellent agreement with the value of $\omega_{e}$ and good agreement with the values of $r_{e}$ and $B_{e}$. The SiO molecule possesses sizable dipole moments of 3.0982 D [41]. Such magnitudes of the dipole moment should be sufficient for sustaining dipole-bound states (DBSs). Extensive experimental and computational studies $[42,43]$ of an extra-electron attachment to a number of polar molecules 
have shown the critical value of the dipole moment required to support a DBS to be $2.5 \mathrm{D}$. The electric dipole moment is also of great utility in the construction of molecular orbital based models of bonding and helping in the search for an understanding of the macroscopic properties of imperfect gases, liquids and solids. The expectation value of this operator is sensitive to the valence electrons and the general predictive quality of the computational methodology.

For the investigated electronic states, we calculated in the present work the permanent dipole $\mu(r)$ for $1.2 \AA \leq r$ $\leq 4 \AA$ (Figures 4 and 5). Each time an adiabatic state loses its ionic character, it becomes again neutral and the corresponding dipole moment tends towards zero.

\subsection{The Vibration-Rotation Calculation}

Within the Born-Oppenheimer approximation, the vibra- tion rotation motion of a diatomic molecule in a given electronic state is governed by the radial Schrödinger equation

$$
\left[\frac{\mathrm{d}^{2}}{\mathrm{~d} r^{2}}+\frac{2 \mu}{\hbar^{2}}\left(E_{v J}-U(r)\right)-\frac{\lambda}{r^{2}}\right] \Psi_{v J}(r)=0
$$

where $r$ is the internuclear distance, $v$ and $J$ are respectively the vibrational and rotational quantum numbers, $\lambda=J(J+1), E_{v J}$ and $\Psi_{v J}$ are respectively the eigenvalue and the eigenfunction of this equation. In the perturbation theory these functions can be expanded as

$$
\begin{gathered}
E_{v J}=\sum_{n=0} e_{n} \lambda^{n} \\
\Psi_{v J}(r)=\sum_{n=0} \Phi_{n}(r) \lambda^{n}
\end{gathered}
$$

with $e_{0}=E_{v}, e_{1}=B_{v}, e_{2}=-D_{v} \cdots, \phi_{0}$ is the pure vibration

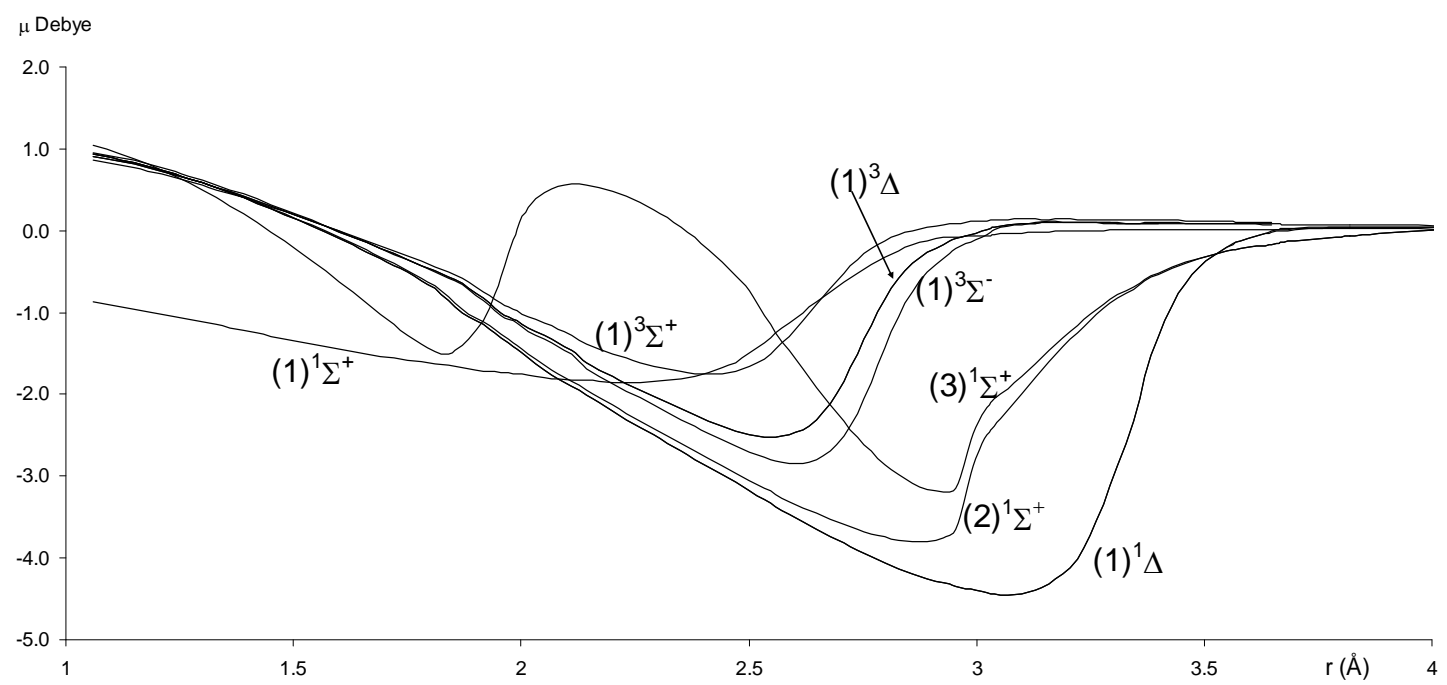

Figure 4. Permanent dipole moment curves of the lowest singlet and triplet and $\Delta$-states of the molecule SiO.

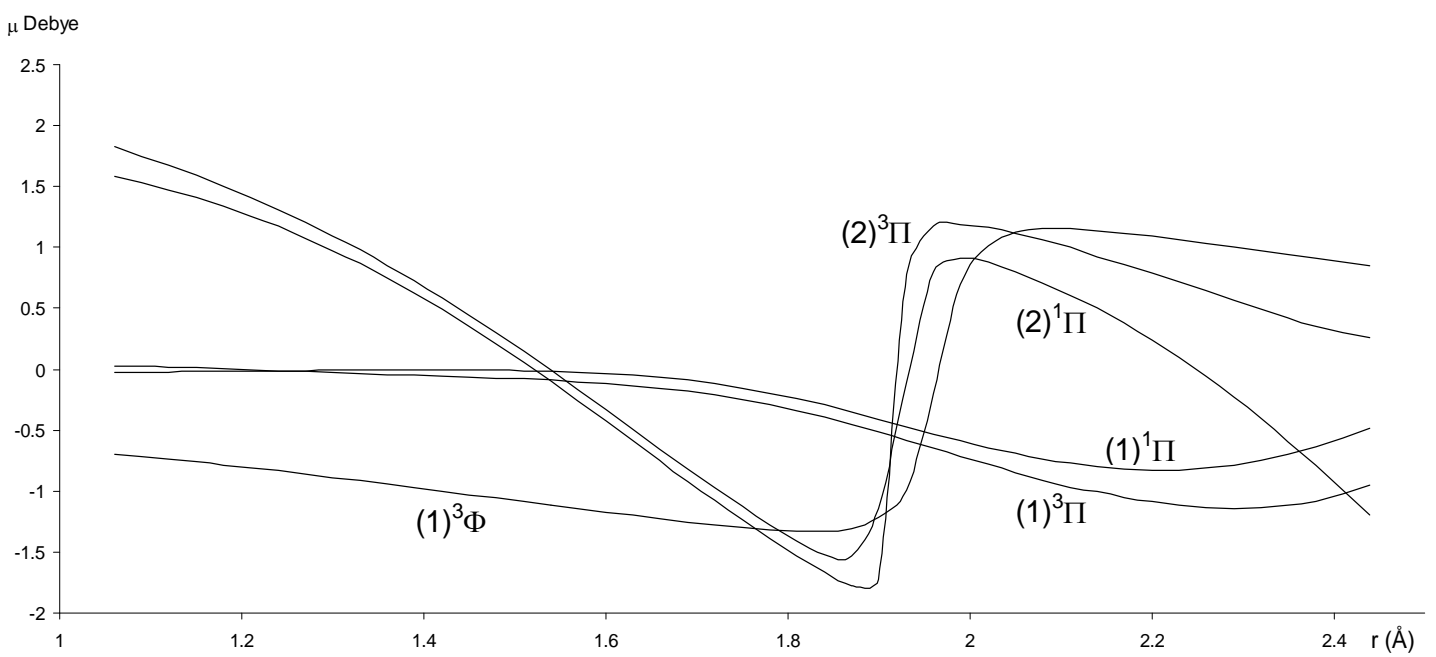

Figure 5. Permanent dipole moment curves of the lowest singlet and triplet $\Sigma$ and $\Delta$-states of the molecule SiO. 
wave function and $\phi_{n}$ its rotational corrections. By replacing Equations (2) and (3) into Equation (1) and since this equation is satisfied for any value of $\lambda$, one can write [24-26]

$$
\begin{aligned}
& \phi_{0}^{\prime \prime}(r)+\left[e_{0}-U(r)\right] \phi_{0}(r)=0 \\
& \phi_{1}^{\prime \prime}(r)+\left[e_{0}-U(r)\right] \phi_{1}(r)=-\left[e_{1}-R(r)\right] \phi_{0}(r) \\
& \phi_{2}^{\prime \prime}(r)+\left[e_{0}-U(r)\right] \phi_{2}(r) \\
& =-\left[e_{1}-R(r)\right] \phi_{1}(r)-e_{2} \phi_{0}(r) \\
& \phi_{n}^{\prime \prime}(r)+\left[e_{0}-U(r)\right] \phi_{n}(r) \\
& =R(r) \phi_{n-1}-\sum_{m=1}^{n} e_{m} \phi_{n-m}(r)
\end{aligned}
$$

where $R(r)=1 / r^{2}$, the first equation is the pure vibrational Schrödinger equation and the remaining equations are called the rotational Schrödinger equations. One may project Equations (7) onto $\phi_{0}$ and find

$$
\left\langle\phi_{0} \mid \phi_{0}\right\rangle e_{1}=\left\langle\phi_{0}\left|\frac{1}{r^{2}}\right| \phi_{0}\right\rangle
$$

$$
\begin{aligned}
& \left\langle\phi_{0} \mid \phi_{0}\right\rangle e_{2}=\left\langle\phi_{0}\left|\frac{1}{r^{2}}\right| \phi_{1}\right\rangle-e_{1}\left\langle\phi_{0} \mid \phi_{1}\right\rangle \\
& \left\langle\phi_{0} \mid \phi_{0}\right\rangle e_{n}=\left\langle\phi_{0}\left|\frac{1}{r^{2}}\right| \phi_{n-1}\right\rangle-\sum_{m=1}^{n-1} e_{m}\left\langle\phi_{n-m} \mid \phi_{0}\right\rangle
\end{aligned}
$$

Once $e_{0}$ is calculated from Equation (4), $e_{1}, e_{2}, e_{3}, \cdots$ can be obtained by using alternatively Equations (5) and (6). By using the canonical functions approach [24-26] and the cubic spline interpolation between each two consecutive points of the PECs obtained from the $a b$ initio calculation of the $\mathrm{SiO}$ molecule, the eigenvalue $E_{v}$, the rotational constant $B_{v}$, the distortion constant $D_{v}$, and the abscissas of the turning point $r_{\min }$ and $r_{\max }$ have been calculated up to the vibration level $v=52$. These values for the state $\mathrm{X}^{1} \Sigma^{+},(1)^{1} \Delta,(1)^{3} \Sigma,(1)^{3} \Pi,(2)^{3} \Pi$ and $(2)^{1} \Pi$

\begin{tabular}{|c|c|c|c|c|c|c|c|c|c|c|c|c|c|c|c|}
\hline & & & $\mathrm{X}^{1} \Sigma^{+}$ & & & & & $(1)^{1} \Delta$ & & & & & $(1)^{3} \Delta$ & & \\
\hline $\mathrm{v}$ & $\begin{array}{c}E_{v} \\
\left(\mathrm{~cm}^{-1}\right)\end{array}$ & $\begin{array}{l}B_{v} \times 10 \\
\left(\mathrm{~cm}^{-1}\right)\end{array}$ & $\begin{array}{l}D_{v} \times 10^{7} \\
\left(\mathrm{~cm}^{-1}\right)\end{array}$ & $\begin{array}{l}r_{\min } \\
(\AA)\end{array}$ & $\begin{array}{l}r_{\max } \\
(\AA)\end{array}$ & $\begin{array}{c}E_{v} \\
\left(\mathrm{~cm}^{-1}\right)\end{array}$ & $\begin{array}{l}B_{v} \times 10 \\
\left(\mathrm{~cm}^{-1}\right)\end{array}$ & $\begin{array}{l}D_{v} \times 10^{7} \\
\left(\mathrm{~cm}^{-1}\right)\end{array}$ & $\begin{array}{l}r_{\min } \\
(\AA)\end{array}$ & $\begin{array}{l}r_{\max } \\
(\AA)\end{array}$ & $\begin{array}{c}E_{v} \\
\left(\mathrm{~cm}^{-1}\right)\end{array}$ & $\begin{array}{l}B_{v} \times 10 \\
\left(\mathrm{~cm}^{-1}\right)\end{array}$ & $\begin{array}{l}D_{v} \times 10^{7} \\
\left(\mathrm{~cm}^{-1}\right)\end{array}$ & $\begin{array}{l}r_{\min } \\
(\AA)\end{array}$ & $\begin{array}{l}r_{\max } \\
(\AA)\end{array}$ \\
\hline 0 & $\begin{array}{l}633.9305^{*} \\
619.3920^{* *}\end{array}$ & $\begin{array}{c}7.10 \\
7.242338\end{array}$ & 8.97 & $\begin{array}{c}1.47494 \\
1.4606053\end{array}$ & $\begin{array}{c}1.5772 \\
1.564163\end{array}$ & 482.1 & 5.56 & 8.81 & 1.664 & 1.789 & 422.8 & 5.56 & 10.4 & 1.660 & 1.788 \\
\hline 1 & $\begin{array}{c}1893.198 \\
1849.0065\end{array}$ & $\begin{array}{c}7.06 \\
7.192007\end{array}$ & 8.96 & $\begin{array}{l}1.44213 \\
1.42765\end{array}$ & $\begin{array}{c}1.61988 \\
1.6076\end{array}$ & 1366.2 & 5.58 & 7.67 & 1.622 & 1.832 & 1232.0 & 5.52 & 9.83 & 1.621 & 1.842 \\
\hline 2 & $\begin{array}{c}3141.771 \\
3066.7266\end{array}$ & $\begin{array}{c}7.01 \\
7.141723\end{array}$ & 8.95 & $\begin{array}{c}1.42083 \\
1.4063274\end{array}$ & $\begin{array}{c}1.6511 \\
1.6396929\end{array}$ & 2282.6 & 5.58 & 7.56 & 1.594 & 1.859 & 2043.9 & 5.48 & 10.5 & 1.595 & 1.882 \\
\hline 3 & $\begin{array}{c}4379.93 \\
4272.5878\end{array}$ & $\begin{array}{c}6.97 \\
7.091488\end{array}$ & 8.93 & $\begin{array}{c}1.40424 \\
1.3897700\end{array}$ & $\begin{array}{c}1.67767 \\
1.6670194\end{array}$ & 3210.5 & 5.55 & 10.2 & 1.572 & 1.893 & 2843.2 & 5.44 & 8.70 & 1.575 & 1.914 \\
\hline 4 & $\begin{array}{c}5607.947 \\
5466.6258\end{array}$ & $\begin{array}{c}6.93 \\
7.041300\end{array}$ & 8.88 & $\begin{array}{c}1.39039 \\
1.3759916\end{array}$ & $\begin{array}{c}1.70143 \\
1.6916551\end{array}$ & 4074.9 & 5.45 & 10.1 & 1.555 & 1.925 & 3652.0 & 5.41 & 9.37 & 1.558 & 1.942 \\
\hline 6 & $\begin{array}{c}8034.551 \\
7819.3743\end{array}$ & $\begin{array}{c}6.84 \\
6.941067\end{array}$ & 8.85 & $\begin{array}{c}1.36776 \\
1.3535482\end{array}$ & $\begin{array}{c}1.74435 \\
1.7360834\end{array}$ & 5755.1 & 5.43 & 5.90 & 1.527 & 1.973 & 5260.6 & 5.33 & 10.4 & 1.531 & 1.995 \\
\hline 7 & $\begin{array}{l}9233.604 \\
8978.156\end{array}$ & $\begin{array}{c}6.80 \\
6.891022\end{array}$ & 8.58 & $\begin{array}{c}1.35817 \\
1.3440662\end{array}$ & $\begin{array}{c}1.76367 \\
1.7566958\end{array}$ & 6620.5 & 5.42 & 7.36 & 1.515 & 1.991 & 6048.5 & 5.30 & 10.2 & 1.519 & 2.019 \\
\hline 8 & $\begin{array}{c}10426.17 \\
10125.257\end{array}$ & $\begin{array}{c}6.76 \\
6.841025\end{array}$ & 8.28 & $\begin{array}{c}1.34938 \\
1.335287\end{array}$ & $\begin{array}{c}1.78219 \\
1.7765575\end{array}$ & 7491.5 & 5.41 & 9.27 & 1.504 & 2.018 & 6826.6 & 5.25 & 8.72 & 1.509 & 2.044 \\
\hline 9 & $\begin{array}{c}11614.53 \\
11260.712\end{array}$ & $\begin{array}{c}6.73 \\
6.791076\end{array}$ & 8.19 & $\begin{array}{c}1.34125 \\
1.327486\end{array}$ & $\begin{array}{c}1.80026 \\
1.7958198\end{array}$ & 8350.0 & 5.34 & 10.1 & 1.494 & 2.035 & 7601.8 & 5.21 & 10.2 & 1.499 & 2.067 \\
\hline 10 & $\begin{array}{c}12799.35 \\
12384.558\end{array}$ & $\begin{array}{c}6.70 \\
0.6 .741174\end{array}$ & 7.56 & $\begin{array}{c}1.33367 \\
1.3201275\end{array}$ & $\begin{array}{c}1.81658 \\
1.8145948\end{array}$ & 9183.0 & 5.31 & 6.32 & 1.485 & 2.052 & 8367.3 & 5.18 & 8.73 & 1.490 & 2.091 \\
\hline 11 & $\begin{array}{l}13985.65 \\
13496.83\end{array}$ & $\begin{array}{c}6.68 \\
0.6 .691321\end{array}$ & 6.67 & $\begin{array}{c}1.32653 \\
1.3132685\end{array}$ & $\begin{array}{c}1.83127 \\
1.8329686\end{array}$ & 10024.6 & 5.31 & 8.76 & 1.476 & 2.077 & 9130.4 & 5.15 & 7.02 & 1.482 & 2.111 \\
\hline
\end{tabular}
(as illustration) are given in Table 2. The comparison of our calculated values of $E_{v}, B_{v}, r_{\min }$ and $r_{\max }$ with the experimental data of Ref.[55] for the ground state $\mathrm{X}^{1} \Sigma^{+}$ shows an excellent agreement for the 35 considered vibrational levels. Similar results are obtained by comparing our calculated values of $B_{v}$ with the calculated Shi et al. [56] for the considered states.

Table 2. Values of $E_{v}, B_{v}, D_{v}$ and $r_{\min }$ and $r_{\max }$ of the SiO molecule. 


\section{Continued}

\begin{tabular}{|c|c|c|c|c|c|c|c|c|c|c|c|c|c|c|c|}
\hline 13 & $\begin{array}{c}16376.97 \\
15686.793\end{array}$ & $\begin{array}{c}6.64 \\
6.591756\end{array}$ & 6.90 & $\begin{array}{c}1.31328 \\
1.3007972\end{array}$ & $\begin{array}{c}1.85926 \\
1.8687714\end{array}$ & 11623.8 & 5.10 & 7.34 & 1.461 & 2.123 & 10675.0 & 5.14 & 6.24 & 1.467 & 2.141 \\
\hline 14 & $\begin{array}{c}17564.86 \\
16764.556\end{array}$ & $\begin{array}{c}6.59 \\
6.542046\end{array}$ & 8.35 & $\begin{array}{c}1.30717 \\
1.2950884\end{array}$ & $\begin{array}{c}1.87471 \\
1.8862999\end{array}$ & 12392.8 & 5.13 & 5.26 & 1.454 & 2.146 & 11457.1 & 5.11 & 11.1 & 1.459 & 2.164 \\
\hline 15 & $\begin{array}{c}18729.64 \\
17830.887\end{array}$ & $\begin{array}{c}6.51 \\
6.492383\end{array}$ & 10.2 & $\begin{array}{c}1.30145 \\
1.2896807\end{array}$ & $\begin{array}{c}1.89247 \\
1.9036325\end{array}$ & 13170.2 & 5.06 & 10.6 & 1.447 & 2.168 & 12221.1 & 5.02 & 17.1 & 1.453 & 2.187 \\
\hline 16 & $\begin{array}{c}19863.12 \\
18885.821\end{array}$ & $\begin{array}{c}6.44 \\
6.442768\end{array}$ & 11.6 & $\begin{array}{c}1.29612 \\
1.2845439\end{array}$ & $\begin{array}{c}1.90996 \\
1.920801\end{array}$ & 13915.0 & 5.00 & 7.12 & 1.441 & 2.189 & 12946.6 & 4.94 & 9.50 & 1.447 & 2.207 \\
\hline 17 & $\begin{array}{c}20969.76 \\
19929.395\end{array}$ & $\begin{array}{c}6.38 \\
6.3932\end{array}$ & 11.3 & $\begin{array}{c}1.2911 \\
1.2796526\end{array}$ & $\begin{array}{c}1.92678 \\
1.9378326\end{array}$ & 14659.1 & 4.99 & 9.25 & 1.435 & 2.210 & 13663.4 & 4.93 & 4.39 & 1.441 & 2.228 \\
\hline 18 & $\begin{array}{c}22064.93 \\
20961.645\end{array}$ & $\begin{array}{c}6.34 \\
6.343681\end{array}$ & 8.96 & $\begin{array}{c}1.28632 \\
1.2749849\end{array}$ & $\begin{array}{c}1.94447 \\
1.954751\end{array}$ & 15395.5 & 4.92 & 10.1 & 1.430 & 2.231 & 14389.7 & 4.90 & 12.8 & 1.435 & 2.249 \\
\hline 19 & $\begin{array}{c}23154.06 \\
21982.604\end{array}$ & $\begin{array}{c}6.30 \\
6.294209\end{array}$ & & $\begin{array}{c}1.28172 \\
1.2705220\end{array}$ & $\begin{array}{c}1.96044 \\
1.9715771\end{array}$ & 16118.8 & 4.89 & 8.64 & 1.425 & 2.252 & 15098.4 & 4.83 & 11.1 & 1.430 & 2.270 \\
\hline 20 & $\begin{array}{l}24234.74 \\
22992.31\end{array}$ & $\begin{array}{c}6.27 \\
6.244785\end{array}$ & 8.05 & $\begin{array}{c}1.2773 \\
1.2662473\end{array}$ & $\begin{array}{c}1.97363 \\
1.9883291\end{array}$ & 16836.7 & 485 & 9.91 & 1.419 & 2.272 & 15794.0 & 4.80 & 6.02 & 1.425 & 2.290 \\
\hline 21 & $\begin{array}{c}25315.7 \\
23990.798\end{array}$ & $\begin{array}{c}6.25 \\
6.195408\end{array}$ & 8.66 & $\begin{array}{c}1.27302 \\
1.2621465\end{array}$ & $\begin{array}{c}1.98686 \\
2.0050237\end{array}$ & 17544.8 & 4.81 & 8.87 & 1.415 & 2.292 & 16491.2 & 4.77 & 11.6 & 1.420 & 2.310 \\
\hline 22 & $\begin{array}{c}26398.66 \\
24978.102\end{array}$ & $\begin{array}{c}6.22 \\
6.14608\end{array}$ & 6.90 & $\begin{array}{c}1.26886 \\
1.2582069\end{array}$ & $\begin{array}{c}2.00346 \\
2.0216754\end{array}$ & 18246.1 & 4.77 & 9.82 & 1.410 & 2.312 & 17176.0 & 4.72 & 9.20 & 1.415 & 2.330 \\
\hline 23 & $\begin{array}{l}27464.85 \\
25954.26\end{array}$ & $\begin{array}{c}6.15 \\
6.096799\end{array}$ & 6.28 & $\begin{array}{c}1.26487 \\
1.254417\end{array}$ & $\begin{array}{c}2.02082 \\
2.0382979\end{array}$ & 18939.0 & 4.73 & 9.20 & 1.406 & 2.332 & 17853.6 & 4.69 & 8.03 & 1.411 & 2.350 \\
\hline 24 & $\begin{array}{c}28503.02 \\
26919.306\end{array}$ & $\begin{array}{c}6.08 \\
6.047566\end{array}$ & 10.0 & $\begin{array}{c}1.2611 \\
1.2507669\end{array}$ & $\begin{array}{c}2.0345 \\
2.0549033\end{array}$ & 19624.4 & 4.69 & 8.90 & 1.401 & 2.352 & 18526.7 & 4.65 & 10.1 & 1.406 & 2.370 \\
\hline 25 & $\begin{array}{c}29530.92 \\
27873.277\end{array}$ & $\begin{array}{c}6.06 \\
5.99838\end{array}$ & 12.7 & $\begin{array}{c}1.25746 \\
1.2472474\end{array}$ & $\begin{array}{c}2.0478 \\
2.0715029\end{array}$ & 20302.9 & 4.66 & 9.37 & 1.397 & 2.372 & 19191.0 & 4.62 & 8.71 & 1.402 & 2.389 \\
\hline 26 & $\begin{array}{c}30563.92 \\
28816.207\end{array}$ & $\begin{array}{c}6.04 \\
5.949243\end{array}$ & 8.91 & $\begin{array}{c}1.25389 \\
1.2438503\end{array}$ & $\begin{array}{c}2.06412 \\
2.0881073\end{array}$ & 20974.0 & 4.62 & 9.34 & 1.393 & 2.391 & 19849.8 & 4.58 & 9.20 & 1.398 & 2.409 \\
\hline 27 & $\begin{array}{c}31582.14 \\
29748.132\end{array}$ & $\begin{array}{c}5.95 \\
5.900153\end{array}$ & 5.12 & $\begin{array}{c}1.25045 \\
1.2405603\end{array}$ & $\begin{array}{c}2.08297 \\
2.1047262\end{array}$ & 21637.9 & 4.58 & 8.83 & 1.389 & 2.411 & 20501.7 & 4.54 & 8.40 & 1.394 & 2.428 \\
\hline 28 & $\begin{array}{c}32558.73 \\
30669.088\end{array}$ & $\begin{array}{c}5.84 \\
5.851111\end{array}$ & 9.66 & $\begin{array}{c}1.24723 \\
1.2373947\end{array}$ & $\begin{array}{c}2.10038 \\
2.1213687\end{array}$ & 22295.2 & 4.55 & 8.87 & 1.385 & 2.430 & 21148.1 & 4.51 & 9.21 & 1.390 & 2.447 \\
\hline 29 & $\begin{array}{c}33508.62 \\
31579.111\end{array}$ & $\begin{array}{c}5.80 \\
5.802116\end{array}$ & 16.7 & $\begin{array}{c}1.24416 \\
1.2343233\end{array}$ & $\begin{array}{c}2.11734 \\
2.1380435\end{array}$ & 22945.8 & 4.51 & 8.98 & 1.382 & 2.450 & 21788.2 & 4.48 & 8.77 & 1.387 & 2.466 \\
\hline 30 & $\begin{array}{c}34457.86 \\
32478.235\end{array}$ & $\begin{array}{c}5.77 \\
5.753169\end{array}$ & 13.3 & $\begin{array}{c}1.24116 \\
1.2313484\end{array}$ & $\begin{array}{c}2.13487 \\
2.1547588\end{array}$ & 23590.2 & 4.48 & 8.54 & 1.378 & 2.469 & 22422.4 & 4.44 & 8.45 & 1.383 & 2.485 \\
\hline 31 & $\begin{array}{c}35394.39 \\
33366.498\end{array}$ & $\begin{array}{c}5.70 \\
5.704270\end{array}$ & 5.98 & $\begin{array}{c}1.23825 \\
1.2284650\end{array}$ & $\begin{array}{c}2.15252 \\
2.1715224\end{array}$ & 24229.3 & 4.45 & 7.09 & 1.375 & 2.490 & 23051.1 & 4.41 & 8.32 & 1.380 & 2.504 \\
\hline 32 & $\begin{array}{c}36308.34 \\
34243.933\end{array}$ & $\begin{array}{c}5.63 \\
5.655419\end{array}$ & 9.95 & $\begin{array}{c}1.23547 \\
1.2256683\end{array}$ & $\begin{array}{c}2.17001 \\
2.1883416\end{array}$ & 24866.1 & 4.43 & 5.56 & 1.372 & 2.506 & 23674.5 & 4.38 & 8.83 & 1.376 & 2.523 \\
\hline 33 & $\begin{array}{c}37209.82 \\
35110.577\end{array}$ & $\begin{array}{c}5.59 \\
5.606616\end{array}$ & 13.0 & $\begin{array}{c}1.23277 \\
1.2229539\end{array}$ & $\begin{array}{c}2.18763 \\
2.2052239\end{array}$ & 25504.3 & 4.42 & 4.20 & 1.368 & 2.518 & 24292.2 & 4.34 & 8.58 & 1.373 & 2.542 \\
\hline 34 & $\begin{array}{c}38099.68 \\
35966.466\end{array}$ & $\begin{array}{c}5.53 \\
5.55786\end{array}$ & 9.68 & $\begin{array}{c}1.23016 \\
1.2203178\end{array}$ & $\begin{array}{c}2.20541 \\
2.2221760\end{array}$ & 26147.4 & 4.42 & 4.69 & 1.365 & 2.532 & 24904.2 & 4.31 & 8.51 & 1.370 & 2.560 \\
\hline 35 & $\begin{array}{c}38973.71 \\
36811.635\end{array}$ & $\begin{array}{c}5.48 \\
5.509152\end{array}$ & 9.69 & $\begin{array}{c}1.22763 \\
1.2177562\end{array}$ & $\begin{array}{c}2.22325 \\
2.2392048\end{array}$ & 26793.2 & 4.40 & 9.08 & 1.362 & 2.552 & 25510.3 & 4.27 & 8.73 & 1.367 & 2.579 \\
\hline 36 & 38100 & 5.53 & 11.3 & 1.230 & 2.205 & 27430.7 & 4.34 & 10.6 & 1.359 & 2.572 & 26110.0 & 4.24 & 9.57 & 1.364 & 2.598 \\
\hline 37 & 38974 & 5.48 & 10.4 & 1.228 & 2.223 & 28046.1 & 4.25 & 1.42 & 1.356 & 2.591 & 26702.2 & 4.20 & 10.1 & 1.361 & 2.618 \\
\hline 38 & 39834 & 5.42 & 10.5 & 1.225 & 2.241 & 28644.7 & 4.22 & 3.26 & 1.353 & 2.609 & 27285.6 & 4.15 & 10.6 & 1.358 & 2.638 \\
\hline 39 & 40682 & 5.37 & 10.9 & 1.223 & 2.259 & 29247.1 & 4.23 & 4.92 & 1.350 & 2.628 & 27858.8 & 4.10 & 11.7 & 1.355 & 2.659 \\
\hline 40 & 41515 & 5.31 & 10.6 & 1.220 & 2.277 & 29850.0 & 4.18 & 10.3 & 1.348 & 2.648 & 28419.6 & 4.04 & & 1.353 & 2.682 \\
\hline 41 & 42335 & 5.26 & 10.9 & 1.218 & 2.296 & 30438.3 & 4.12 & 9.22 & 1.345 & 2.666 & 28964.6 & 3.97 & & 1.350 & 2.707 \\
\hline
\end{tabular}


Continued

\begin{tabular}{|c|c|c|c|c|c|c|c|c|c|c|c|c|c|c|c|}
\hline 42 & 43142 & 5.20 & 10.9 & 1.216 & 2.315 & 31019.3 & 4.11 & 4.67 & 1.342 & 2.685 & 29488.0 & 3.87 & & 1.348 & 2.735 \\
\hline 43 & 43935 & 5.15 & 11.1 & 1.214 & 2.334 & 31600.6 & 4.08 & 10.0 & 1.340 & 2.704 & 29979.2 & 3.72 & & 1.346 & 2.771 \\
\hline 44 & 44714 & 5.09 & 11.1 & 1.212 & 2.353 & 32173.2 & 4.04 & 8.83 & 1.337 & 2.723 & 30415.2 & 3.45 & & 1.344 & 2.828 \\
\hline 45 & 45480 & 5.03 & 11.4 & 1.210 & 2.372 & 32739.0 & 4.01 & 6.34 & 1.335 & 2.742 & 30756.4 & 3.00 & & 1.342 & 2.922 \\
\hline 46 & 46231 & 4.97 & 11.5 & 1.208 & 2.392 & 33302.0 & 3.98 & 9.57 & 1.333 & 2.761 & & & & & \\
\hline 47 & 46969 & 4.91 & 11.7 & 1.206 & 2.412 & 33858.0 & 3.95 & 7.67 & 1.330 & 2.779 & & & & & \\
\hline 48 & 47692 & 4.85 & & 1.204 & 2.432 & 34409.1 & 3.92 & 7.37 & 1.328 & 2.798 & & & & & \\
\hline 49 & 48400 & 4.79 & & 1.203 & 2.453 & 34956.0 & 3.89 & 7.90 & 1.326 & 2.817 & & & & & \\
\hline 50 & 49093 & 4.73 & & 1.201 & 2.475 & 35497.9 & 3.87 & 6.76 & 1.324 & 2.836 & & & & & \\
\hline 51 & 49770 & 4.66 & & 1.199 & 2.497 & & & & & & & & & & \\
\hline 52 & 50432 & 4.60 & & 1.198 & 2.519 & & & & & & & & & & \\
\hline \multicolumn{6}{|c|}{$(1)^{3}$} & \multicolumn{5}{|c|}{$(2)^{3}$} & \multicolumn{5}{|c|}{$(2)^{1}$} \\
\hline 0 & 263.3 & 5.17 & 20.6 & 1.707 & 1.868 & 440.6 & 5.93 & 10.0 & 1.610 & 1.731 & 444.7 & 5.99 & 9.90 & 1.601 & 1.721 \\
\hline 1 & 775.3 & 5.08 & 18.3 & 1.662 & 1.938 & & & & & & 1374.6 & 5.96 & 8.90 & 1.564 & 1.769 \\
\hline 2 & 1290.2 & 5.01 & 20.1 & 1.635 & 1.995 & & & & & & 2322.9 & 5.94 & 8.95 & 1.539 & 1.804 \\
\hline 3 & 1787.5 & 4.89 & 21.6 & 1.614 & 2.047 & & & & & & & & & & \\
\hline 4 & 2264.3 & 4.81 & 16.5 & 1.598 & 2.097 & & & & & & & & & & \\
\hline 5 & 2740.5 & 4.74 & 17.6 & 1.584 & 2.130 & & & & & & & & & & \\
\hline 6 & 3211.3 & 4.68 & 19.6 & 1.572 & 2.175 & & & & & & & & & & \\
\hline 7 & 3666.0 & 4.53 & 31.6 & 1.561 & 2.222 & & & & & & & & & & \\
\hline 8 & 4082.1 & 4.41 & 1.68 & 1.552 & 2.267 & & & & & & & & & & \\
\hline
\end{tabular}

"First entry for the present work; ${ }^{* *}$ Second entry Refs. [51,54].

\section{Conclusion}

In the present work, the ab initio investigation for the 20 low-lying singlet and triplet electronic states of the $\mathrm{SiO}$ molecule has been performed via CAS-SCF/MRCI method. The potential energy and the dipole moment curves have been determined along with the spectroscopic constants $T_{e}, r_{e}, \omega_{e}, \omega_{e} x_{e}$ and the rotational constant $B_{e}$ for the lowest-lying electronic states. The comparison of our results, for the ground and excited states, with those obtained experimentally in literature shows an overall very good agreement, while the agreement with the theoretical data depends on the technique of calculation. By using the canonical functions approach [24-26], the eigenvalue $E_{v}$, the rotational constant $B_{v}$, and the abscissas of the turning points $r_{\min }$ and $r_{\max }$ have been calculated up to the vibrational level $v=52$ with an excellent agreement by comparing with the available results in literature. Eight electronic states have been investigated in the present work for the first time. These newly obtained results maybe confirmed by the investigation of new experimental works on this molecule.

\section{REFERENCES}

[1] R. W. Wilson, A. A. Penzias, K. B. Jefferts, M. Kutner and P. Thaddeus, "Discovery of Interstellar Silicon Monoxide," The Astrophysical Journal, Vol. 167, 1971, pp. L97-L100. doi:10.1086/180769

[2] J. Martin-Pintado, R. Bachiller and A. Fuente, "SiO Emission as a Tracer of Shocked Gas in Molecular Outflows," Astronomy and Astrophysics, Vol. 254, No. FEB (I), 1992, pp. 315-326.

[3] D. R. Flower and G. P. des Forêt, "Non-Thermal Sputtering of Interstellar Grains in Magnetohydrodynamic Shocks," Monthly Notices of the Royal Astronomical Society, Vol. 275, No. 4, 1995, pp. 1049-1056.

[4] P. Schilke, C. M. Walmsley, G. P. des Forêts and D. R. Flower, "SiO Production in Interstellar Shocks," Astron- 
omy and Astrophysics, Vol. 321, No. FEB (I), 1997, pp. 293-304.

[5] S. D. Le Picard, A. Canosa, G. P. des Forêts, C. Rebrion-Rowe and B. R. Rowe, "The $\mathrm{Si}\left({ }^{3} \mathrm{P}_{\mathrm{J}}\right)+\mathrm{O}^{2}$ Reaction: A Fast Source of $\mathrm{SiO}$ at Very Low Temperature; CRESU Measurements and Interstellar Consequences," Astronomy and Astrophysics, Vol. 372, No. 3, 2001, pp. 10641070.

[6] F. Dayou and A. Spielfiedel, “Ab Initio Calculation of the Ground ( ${ }^{1}$ ') Potential Energy Surface and Theoretical Rate Constant for the $\mathrm{Si}+\mathrm{O}_{2} \mid \mathrm{SiO}+\mathrm{O}$ Reaction," Journal of Chemical Physics, Vol. 119, No. 8, 2003, pp. 4237-4250. doi:10.1063/1.1594172

[7] I. Jiménez-Serra, J. Martin-Pintado, A. Rodriguez-Franco and S. Martin, "Grain Evolution across the Shocks in the L1448-mm Outflow," The Astrophysical Journal Letters, Vol. 627, No. 2, 2005, 2005, pp. L121-L124.

[8] N. T. X. Huynh, V.V. Hoang and H. Zung, "Evolution of Structure of $\mathrm{SiO}_{2}$ Nanoparticles upon Cooling from the Melt," PMC Physics B, 2008, Article ID: 16. doi:10.1186/1754-0429-1-16

[9] I. S. Altman, D. Lee, J. D. Chung, J. Song and M. Choi1, "Light Absorption of Silica Nanoparticles," Physical Review B, Vol. 63, No. 16, 2001, pp. 161402(R)-161402(R).

[10] K. P. Huber and G. Herzberg, "Constants of Diatomic Molecules," Van Nostrand, Reinhold, 1979.

[11] T. G. Heil and S. H. Schaefer, "Potential Curves for the Valence-Excited States of Silicon Monoxide. A Theoretical Study," Journal of Chemical Physics, Vol. 56, No. 2, 1972, pp. 958-969. doi:10.1063/1.1677254

[12] H. Varambhia, M. Gupta, A. Faure, K. L. Baluja and J. Tennyson, "Electron Collision with the Silicon Monoxide (SiO) Molecule Using the R-Matrix Method," Journal of Physics B: Atomic, Molecular and Optical Physics, Vol. 42, No. 9, 2009, Article ID: 095204. doi:10.1088/0953-4075/42/9/095204

[13] J. R. Smith, H. Schlosser, W. Leaf, J. Ferrante, J. H. Rose, "Connection between Energy Relations of Solids and Molecules," Physical Review A, Vol. 39, No. 2, 1989, pp. 514-517. doi:10.1103/PhysRevA.39.514

[14] S. Abdul-Al, M. Korek and A. R. Allouche, "Theoretical Electronic Structure of the Lowest-Lying States of the YI Molecule," Chemical Physics, Vol. 308, No. 1-2, 2005, pp. 1-6. doi:10.1016/j.chemphys.2004.07.032

[15] M. Korek, Y. A. Moghrabi and A. R. Allouche, "Theoretical Calculation of the Excited States of the KCs Molecule Including the Spin-Orbit Interaction," Journal of Chemical Physics, Vol. 124, No. 9, 2006, Article ID: 094309. doi:10.1063/1.2173239

[16] M. Korek, S. Bleik and A. R. Allouche, "Theoretical Calculation of the Low Laying Electronic States of the Molecule NaCs with Spin-Orbit Effect," Journal of Chemical Physics, Vol. 126, No. 12, 2007, Article ID: 124313. doi: $10.1063 / 1.2710257$

[17] F. Taher-Mansour, A. R. Allouche, M. Korek, "Theoretical Electronic Structure of the Lowest-Lying States of $\mathrm{ScCl}$ Molecule below 22,500 $\mathrm{cm}^{-1}$," Journal of $\mathrm{Mo}$ lecular Spectroscopy, Vol. 248, No. 1, 2008, pp. 61-65. doi:10.1016/j.jms.2007.11.012

[18] M. Korek, S. Kontar, F. Taher-Mansour and A. R. Allouche, "Theoretical Electronic Structure of the Molecule ScI," International Journal of Quantum Chemistry, Vol. 109, No. 2, 2009, pp. 236-242. doi:10.1002/qua.21779

[19] M. Korek, S. Al-Shawa and G. Younes, "Theoretical Calculation of the Electronic Structure of the Molecule $\mathrm{LiRb}$ Including the Spin-Orbit Interaction," Journal of Molecular Structure: THEOCHEM, Vol. 899, No. 1-3, 2009, pp. 25-31. doi:10.1016/j.theochem.2008.12.006

[20] M. Korek and S. N. Abdul-Al, "Rovibrational Study and Dipole Moment Calculation of the Molecule YF with Spin-Orbit Interaction," Chemical Physics, Vol. 355, No. 2-3, 2009, pp. 130-134. doi:10.1016/j.chemphys.2008.11.022

[21] A. Hamdan and M. Korek, "Theoretical Calculation of the Low-Lying Sextet Electronic States of CrF Molecule," Chemical Physics, Vol. 369, No. 1, 2010, pp. 13-18. doi:10.1016/j.chemphys.2010.01.023

[22] A. Hamdan and M. Korek, "Theoretical Calculation of the Low-Lying Quartet States of the CrF Molecule," Canadian Journal of Chemistry, Vol. 89, No. 10, 2011, pp. 1304-1311. doi:10.1139/v11-082

[23] A. Hamdan and M. Korek, "Theoretical Study with Vibration-Rotation and Dipole Moment Calculations of Quartet States of the $\mathrm{CrCl}$ Molecule," International Journal of Quantum Chemistry, Vol. 111, No. 12, 2011, pp. 2960-2965. doi:10.1002/qua.22602

[24] H. Kobeissi, M. Korek and M. Dagher, "On the Computation of Diatomic Centrifugal Distortion Constants: Exact Solutions for Initial Value Problems," Journal of Molecular Spectroscopy, Vol. 138, No. 1, 1989, pp. 1-12. doi:10.1016/0022-2852(89)90092-1

[25] M. Korek and H. Kobeissi, "Highly Accurate Diatomic Centrifugal Distortion Constants for High Orders and High Levels," Journal of Computational Chemistry, Vol. 13, No. 9, 1992, pp. 1103-1108. doi:10.1002/jcc.540130909

[26] M. Korek, “A One Directional Shooting Method for the Computation of Diatomic Centrifugal Distortion Constants," Computer Physics Communications, Vol. 119, No. 2-3, 1999, pp. 169-178. doi:10.1016/S0010-4655(98)00180-5

[27] T. H. Dunning, "Gaussian Basis Sets for Use in Correlated Molecular Calculations. I. The Atoms Boron through Neon and Hydrogen," Journal of Chemical Physics, Vol. 90, No. 2, 1989, pp. 1007-1024. doi:10.1063/1.456153

[28] N. Godbout, D. R. Salahub, J. Andzelm and E. Wimmer, "Optimization of Gaussian-Type Basis Sets for Local Spin Density Functional Calculations. Part I. Boron through Neon, Optimization Technique and Validation," Canadian Journal of Chemistry, Vol. 70, No. 2, 1992, pp. 560-571. doi:10.1139/v92-079

[29] H. J. Werner, P. J. Knowles, R. Lindh, F. R. Manby, M. Schütz, P. Celani, T. Korona, G. Rauhut, R. D. Amos, A. Bernhardsson, A. Berning, D. L. Cooper, M. J. O. Deegan, A. J. Dobbyn, F. Eckert, C. Hampel, G. Hetzer, A. W. Lloyd, S. J. McNicholas, W. Meyer, M. E. Mura, A. Nicklaß, P. Palmieri, R. Pitzer, U. Schumann, H. Stoll, A. 
J. Stone, R. Tarroni and T. Thorsteinsson, "MOLPRO Is a Package of Ab Initio Programs," 2008.

http://www.molpro.net/info/molpro2006.1/molpro_manual

[30] A. R. Allouche, "Gabedit-A Graphical User Interface for Computational Chemistry Softwares," Journal of Computational Chemistry, Vol. 32, No. 1, 2011, pp. 174-182. doi: $10.1002 /$ jec. 21600

[31] M. Friesen, M. Junker, A. Zumbusch and H. Schnöckel, "Raman-Spectroscopy of Oligomeric SiO Species Isolated in Solid Methane," Journal of Chemical Physics, Vol. 111, No. 17, 1999, pp. 7881-7888. doi:10.1063/1.480123

[32] C. E. Moore, "Atomic Energy Levels," National Bureau of Standards Circular, Washington DC, 1949.

[33] P. Botschwina and P. Rosmus, "An Ab Initio Calculation of Spectroscopic Properties of $\mathrm{SiO}$ and $\mathrm{HOSi}^{+}$," Journal of Chemical Physics, Vol. 82, No. 3, 1985, pp. 1420-1427. doi: $10.1063 / 1.448465$

[34] S. R. Langhoff and J. O. Arnold, "Theoretical Study of the $\mathrm{X}^{1+}, \mathrm{A}^{1}, \mathrm{C}^{1-}$, and $\mathrm{E}^{1+}$ States of the SiO Molecule," Journal of Chemical Physics, Vol. 70, No. 2, 1979, pp. 852-863. doi:10.1063/1.437491

[35] H. J. Werner, P. Rosmus and M. Grimm, “Ab Initio Calculations of Radiative Transition Probabilities in the $\mathrm{X}^{1} \sigma^{+}$ State of $\mathrm{SiO}$ and the $\mathrm{X}^{2} \sigma^{+}$and $\mathrm{A}^{2} \Pi$ states of $\mathrm{SiO}^{+}$," Chemical Physics, Vol. 73, No. 1-2, 1982, pp. 169-178. doi:10.1016/0301-0104(82)85158-6

[36] T. Törring, Zeitschrift für Naturforschung, Vol. 23A, 1968, pp. 777-778.

[37] E. L. Manson Jr., W. W. Clark, F. C. Delucia and W. Gordy, "Millimeter Spectrum and Molecular Constants of Silicon Monoxide," Physical Review A, Vol. 15, No. 1, 1977, pp. 223-226. doi:10.1103/PhysRevA.15.223

[38] F. J. Lovas, A. G. Maki and W. B. Olson, "The Infrared Spectrum of $\mathrm{SiO}$ near $1240 \mathrm{~cm}^{-1}$ and Its Relation to the Circumstellar SiO Maser," Journal of Molecular Spectroscopy, Vol. 87, No. 2, 1981, pp. 449-458. doi:10.1016/0022-2852(81)90416-1

[39] G. L. Gutsev, P. Jena and R. J. Bartlett, "Two ThermoDynamically Stable States in $\mathrm{SiO}^{-}$and $\mathrm{PN}^{-}$," Physical Review A, Vol. 58, No. 6, 1998, pp. 4972-4974. doi:10.1103/PhysRevA.58.4972

[40] S. Chattopadhyaya, A. Chattopadhyaya and K. Kummar Das, "Configuration Interaction Study of the Low-Lying Electronic States of Silicon Monoxide," The Journal of Physical Chemistry A, Vol. 107, No. 1, 2003, pp. 148-158. doi:10.1021/jp021845v

[41] J. W. Raymonda, J. S. Muenter and W. A. Klemperer, "Electric Dipole Moment of $\mathrm{SiO}$ and GeO," Journal of Chemical Physics, Vol. 52, No. 7, 1970, pp. 3458-3462. doi:10.1063/1.1673510

[42] G. L. Gutsev and L. Adamowicz, "Electronic and Geometrical Structure of Dipole-Bound Anions Formed by Polar Molecules," Journal of Chemical Physics, Vol. 99, No. 36, 1995, pp. 13412-13421. doi:10.1021/j100036a015

[43] C. Desfrançois, H. Abdoul-Carime and J. P. Schermann, "Ground-State Dipole-Bound Anions," International Jour- nal of Modern Physics B, Vol. 10, No. 12, 1996, pp. 1339 1395. doi:10.1142/S0217979296000520

[44] M. E. Sanz, M. C. McCarthy and P. Thaddeus, "Rotational Transitions of SO, SiO, and SiS Excited by a Discharge in a Supersonic Molecular Beam: Vibrational Temperatures, Dunham Coefficients, Born-Oppenheimer Breakdown, and Hyperfine Structure," Journal of Chemical Physics, Vol. 119, No. 22, 2003, pp. 11715-11727. doi:10.1063/1.1612481

[45] G. Hager, R. Harris and S. G. Hadley, "The $\mathrm{a}^{3} \Sigma^{+} \rightarrow \mathrm{X}^{1} \Sigma^{+}$ and $\mathrm{b}^{3} \Pi \rightarrow \mathrm{X}^{1} \Sigma^{+}$Band Systems of $\mathrm{SiO}$ and the $\mathrm{a}^{3} \Sigma^{+} \rightarrow \mathrm{X}^{1} \Sigma^{+}$ Band System of $\mathrm{GeO}$ Observed in Chemiluminescence," Journal of Chemical Physics, Vol. 63, No. 7, 1975, pp. 2810-2821. doi:10.1063/1.431713

[46] H. Bredohl, R. Cornet, I. Dubois and F. Remy, "The $\mathrm{a}^{3} \Pi_{\mathrm{j}}-\mathrm{X}^{1} \mathrm{~B}^{+}$transition of SiO," Journal of Physics B: Atomic and Molecular Physics, Vol. 7, No. 3, 1974, pp. L66L69. doi:10.1088/0022-3700/7/3/019

[47] S. Nagaraj and R. D. Verma, " $A^{3} \Sigma-{ }^{3} \Pi$ Transition of the $\mathrm{SiO}$ Molecule," Canadian Journal of Physics, Vol. 48, No. 12, 1970, pp. 1436-1440. doi:10.1139/p70-181

[48] R. Field, A. Lagerqvist and I. Renhorn, "The Spectrum of $\mathrm{Si}^{18} \mathrm{O}$ in the Vacuum Ultraviolet Region," Journal of Molecular Spectroscopy, Vol. 49, No. 1, 1974, pp. 157166. doi:10.1016/0022-2852(74)90104-0

[49] D. L. Hildenbrand, "The Gaseous Equilibrium $\mathrm{Ge}+\mathrm{SiO}=$ $\mathrm{GeO}+\mathrm{Si}$ and the Dissociation Energy of SiO," High Temperature Science, Vol. 4, 1972, pp. 244-245.

[50] J. Oddershede and N. Elander, "Spectroscopic Constants and Radiative Lifetimes for Valence Excited Bound States in SiO," Journal of Chemical Physics, Vol. 65, No. 9, 1976, pp. 3495-3505. doi:10.1063/1.433577

[51] A. Lagerqvist, I. Renhorn and N. Elander, "The Spectrum of $\mathrm{SiO}$ in the Vacuum Ultraviolet Region," Journal of Molecular Spectroscopy, Vol. 46, No. 2, 1973, pp. 285315. doi:10.1016/0022-2852(73)90043-X

[52] N. Elander and A. Lagerqvist, "On the $\mathrm{E}^{1} \Sigma^{+}-\mathrm{X}^{1} \Sigma^{+}$System of $\mathrm{SiO}$ in the Vacuum Ultraviolet Region," Physica Scripta, Vol. 3, No. 6, 1971, pp. 267-271. doi:10.1088/0031-8949/3/6/005

[53] J. Klache, "Trends in Ground and Excited State Electron Affinities of Group 14, 15, and 16 Mixed Diatomic Anions: A Computational Study," Physical Chemistry Chemical Physics, Vol. 4, No. 14, 2002, pp. 3311-3317. doi:10.1039/b201498j

[54] A. Lagerqvist, I. Renhorn and N. Elander, "The Spectrum of $\mathrm{Si}^{18} \mathrm{O}$ in the Vacuum Ultraviolet Region," Journal of Molecular Spectroscopy, Vol. 49, No. 1, 1974, pp. 157166. doi:10.1016/0022-2852(74)90104-0

[55] R. Tipping and C. Chakerian Jr., "Vibration-Rotation Intensities of SiO," Journal of Molecular Spectroscopy, Vol. 88 , No. 2, 1981, pp. 352-363. doi:10.1016/0022-2852(81)90185-5

[56] D. Shi, W. Li, J. Sun and Z. Zhu, "MRCI Study on the Spectroscopic Parameters and Molecular Constants of the $\mathrm{X}^{1} \Sigma^{+}, a^{3} \Sigma^{+}, \mathrm{A}^{1} \Pi$ and $\mathrm{C}^{1} \Sigma^{-}$Electronic States of the $\mathrm{SiO}$ Molecule," Spectrochimica Acta A, Vol. 87, 2012, pp. 96-105. doi:10.1016/i.saa.2011.11.017 